\section{Hemocromatosis esporádica con intensa siderosis hepatocelular}

\section{Sr. Director:}

La hemocromatosis (HC) es una enfermedad relativamente común, con una prevalencia estimada entre $1 / 300$ y $1 / 500$ individuos en caucásicos. Si permanece sin diagnosticar, determina la aparición de complicaciones en la $5^{\mathrm{a}}-6^{\mathrm{a}}$ década de la vida (cirrosis, miocardiopatía, diabetes, etc.). La enfermedad suele ser detectada en estadios avanzados, cuando ya se han desarrollado las alteraciones orgánicas (1). Describimos el caso de un varón joven al que se le descubrió una HC en una analítica de rutina.

Varón de 20 años, sin antecedentes personales de interés, al que se le detecta un aumento de la sideremia y saturación de la transferrina, por lo que es enviado a la Consulta de Hematología. En la anamnesis destaca la existencia de hepatopatía no filiada en varios miembros de la familia paterna. La exploración física fue anodina. Entre los datos analíticos destacaban: sideremia $251 \mathrm{mg} / \mathrm{dl}(\mathrm{N}: 40-160)$, transferrina $244 \mathrm{mg} / \mathrm{dl}(\mathrm{N}$ : 200-400), indice de saturación de la transferrina $81 \%$ (N: $15-$ 40) y ferritina $707 \mathrm{ng} / \mathrm{ml}$ (N: 15-300), con normalidad del hemograma, morfología y el resto de parametros bioquímicos, incluyendo glucemia y sobrecarga oral de glucosa, hormonas tiroideas, FSH, LH y estudio ecocardiográfico. El fenotipo HLA del paciente fue: A3, Cw7,B7 / A1, Cw7, B50; (pareno A3, Cw7, B7 / A32, Cw7, B51 y materno A1, Cw6, B50 / A3, $\mathrm{Cw}-, \mathrm{B} 65$. La resonancia nuclear magnética (RNM) (Fig. 1) demostró hipointensidad manifiesta del parénquima hepático sobre todo en T2, concordante con depósitos de hierro. La biopsia hepática confirmó siderosis intracelular grado IV, sin fibrosis. Con todos estos datos se hizo el diagnóstico de hemocromatosis hereditaria, sin afectación familiar clínica ni analítica. Desde entonces al paciente se le han realizado sangrías semanales de $500 \mathrm{cc}$ hasta mantener los niveles de ferritina entre $10-15 \mathrm{ng} / \mathrm{ml}$, encontrandose asintomático diez meses después del diagnóstico.

La HC es una enfermedad hereditaria que se transmite de forma autosómica recesiva caracterizada por una absorción intestinal excesiva de hierro (1). Clínicamente, sólo se manifiesta en sujetos homozigotos, siendo excepcional en los heterozigotos, a no ser que se acompañe de otras enfermedades que

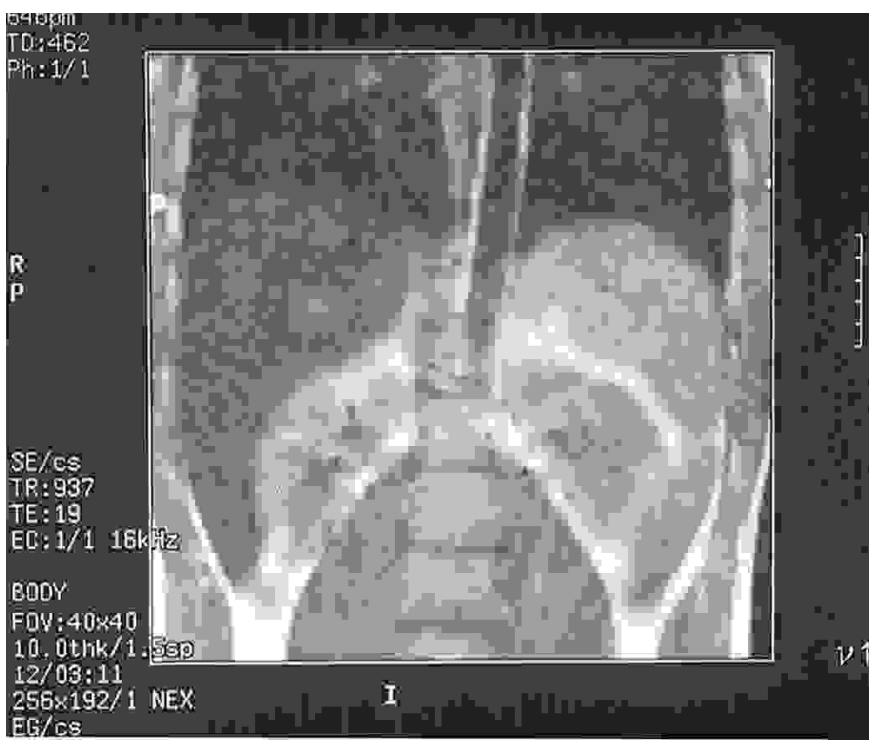

Fig. 1. O bsérvese la hipointensidad del higado. RNM . alteren el metabolismo férrico (esferocitosis hereditaria, $\beta$-talasemia heterozigota, porfiria cutánea tarda, etc.). Recientemente, Feder et al han descubierto el que parece ser el gen responsable de la HC, el HLA-H (2). El diagnóstico clínico de la HC es inespecífico, estableciendose la sospecha ante un incremento de los valores de saturación de la transferrina y de la ferritina. Para que un sujeto sea considerado como homozigoto, hay que demostrar el depósito de hierro en el hígado (biopsia hepática). La RNM también permite un diagnóstico de sospecha (hipointensidad difusa del parénquima hepático), aunque sin poder realizar una estimación cuantitativa. En nuestro caso fue muy indicativa de la siderosis parenquimatosa hepática, que quedó plenamente confirmada en el estudio histológico. Es interesante resaltar el fenotipo HLA del paciente, ya que siendo la madre portadora del haplotipo A3, transmitió al hijo el haplotipo A1B50, que hasta la fecha ha sido escasamente relacionado con la enfermedad (3). Por dicho motivo la madre está siendo revisada periódicamente ante la posibilidad que fuese homozigótica asintomática, protegida de la $\mathrm{HC}$ por las pérdidas menstruales de hierro.

Como pauta de tratamiento hemos sometido al paciente a sangrias semanales de $500 \mathrm{cc}$, con monitorización de los niveles de hemoglobina y ferritina. Hasta la fecha el paciente ha mostrado una excelente tolerancia a las mismas. Asimismo se ha vacunado contra el virus de la hepatitis B, para evitar, en la medida de lo posible, la afectación hepática sobreañadida (4).

\section{F. J. Jiménez Gonzalo, M. Medina Pérez, J. Pérez Martínez, R. Villa Caro}

Servicios de Hematología, Anatomía Patológica y Medicina Interna. Hospital de la Merced. Osuna. Sevilla

1. Rodríguez A, Pérez F, González F. Hemocromatosis idiopática (análisis de 19 casos). An Med Intern 1997; 14: 20-23.

2. Feder JN, Gnirke A, Thomas W, et al. A novel MHC class I-like gene is mutated in patients with hereditary haemochromatosis. Nat Genet 1996 $13: 399-408$

3. Bulaj ZJ, Griffen LM, Jorde LB, et al. Clinical and biochemical abnormalities in people heterozygous for haemochromatosis. N Engl J Med 1996; 335: 1799-1805

4. Camaschella C, Piperino A. Hereditary hemochromatosis: recent advances in molecular genetics and clinical management. Hematologica 1997; 82: $77-84$.

\section{Endocarditis bacteriana en un adulto con comunicación interventricular congénita}

\section{Sr. Director:}

En la edad pediátrica las malformaciones cardíacas congénitas (MCC) constituyen las cardiopatías de mayor riesgo para el desarrollo de endocarditis bacteriana $(1,2)$, sin embargo este tipo de lesiones se encuentran con mucha menor frecuencia en adultos, en los que la endocarditis ocurre preferentemente sobre valvulopatía reumática o degenerativa.

A continuación describimos el caso de un adulto con una comunicación interventricular (CIV) congénita que presentó una endocarditis por enterococo.

Varón de 43 años con una CIV congénita diagnosticada 25 años antes al que se le practicó una hemicolectomía derecha por un adenocarcinoma de colon. Durante el postoperatorio presentó 
fiebre elevada obteniéndose cultivos positivos para Enterococcus faecalis en orina y exudados procedentes de los redones, los hemocultivos fueron negativos. Con tratamiento antibiótico la evolución fue satisfactoria dándose de alta trece días después de la intervención. Una semana después comenzó a presentar fiebre sin otra sintomatología y, de forma ambulatoria, se practicaron una radiografía de tórax y una TAC abdominal que fueron normales, instaurándose tratamiento con ciprofloxacino oral. Tras varios días de tratamiento el paciente continuaba febril y con deterioro progresivo de su estado general por lo que se decidió su ingreso hospitalario. A la exploración física el paciente estaba febril $\left(39^{\circ} \mathrm{C}\right)$ y presentaba un soplo holosistólico en borde esternal izquierdo irradiado en barra, el resto de la exploración fue anodina. De los datos analíticos destacaban: VSG $86 \mathrm{~mm} / 1^{\mathrm{a}} \mathrm{h}$,

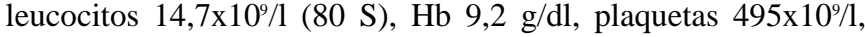
valores del autoanalizador SMAC normales, fibrinógeno 618 $\mathrm{mg} / \mathrm{dl}$, PCR $206 \mathrm{mcg} / \mathrm{ml}$ (vn: 0-5) y factor reumatoide (látex) 45 $\mathrm{Ul} / \mathrm{ml}$. Las radiografías de tórax y abdomen, y una nueva TAC abdominal fueron normales. El urinocultivo fue negativo y tres hemocultivos fueron positivos para Enterococcus faecalis. En la ecocardiografía transtorácica no se objetivaron vegetaciones por lo que se practicó una ecocardiografía transesofágica que mostró una CIV membranosa subaórtica de pequeño tamaño con cortocircuito izquierda-derecha y una imagen sugestiva de vegetación de 13 × $5 \mathrm{~mm}$ en la vertiente ventricular derecha del tabique inmediatamente por debajo de la CIV (Fig. 1). Se completaron seis semanas de tratamiento con ampicilina y gentamicina con buena respuesta clinica desde su inicio, los hemocultivos de control fueron negativos y en una nueva ecocardiografía no se observaron cambios.

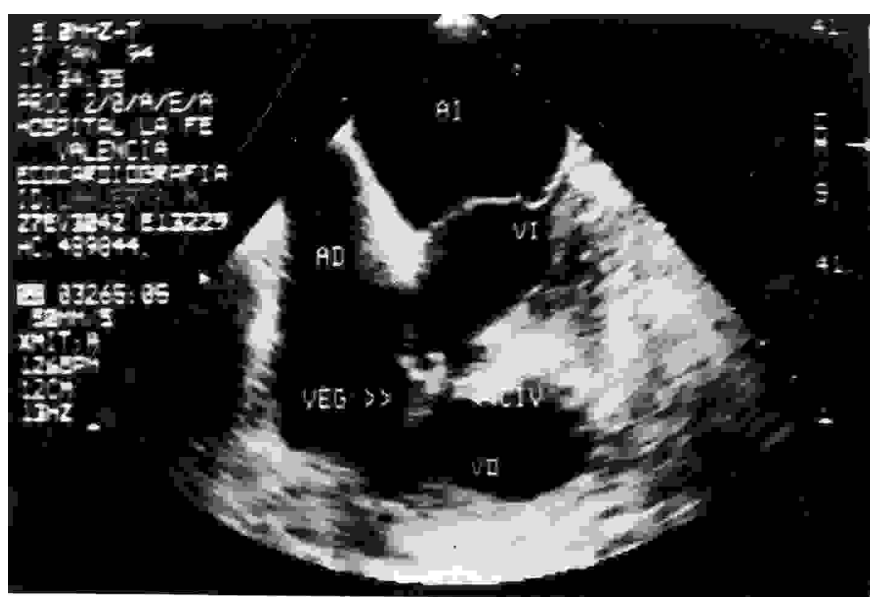

Fig. 1. Ecocardiografía transesofágica: plano no estandarizado en el que se observa la vegetación a nivel de la vertiente ventricular derecha de la CIV. (AI: aurícula izquierda, AD: aurícula derecha, VI: ventrículo izquierdo, VD: Ventrículo derecho, VEG: vegetación, CIV: comunicación interventricular).

Según diferentes series que incluyen pacientes de todas las edades, las MCC constituyen la patología cardiaca predisponente para endocarditis en el $10-13 \%$ de los casos (2-5), siendo mucho más frecuentes las endocarditis sobre valvulopatía reumática o degenerativa y sobre prótesis valvulares. La MCC que se asoció con mayor frecuencia a endocarditis fue la CIV aislada o asociada a malformaciones más complejas. La CIV es la MCC más frecuente en el momento del nacimiento ocupando el tercer lugar en el adulto dada la alta mortalidad que presentan estos pacientes si no se someten a corrección quirúrgica. La CIV del adulto suele ser de pequeño tamaño condicionando cortocircuitos izquierdaderecha que no provocan grandes sobrecargas de volumen ni hipertensión pulmonar. En la endocarditis sobre CIV las vegeta- ciones se sitúan en la pared libre del ventrículo derecho o en la valva septal de la válvula tricúspide ya que son los puntos donde choca el chorro del cortocircuito, es menos frecuente que la vegetación se sitúe en la pared de la propia comunicación como ocurrió en nuestro caso. El riesgo de endocarditis sobre CIV se duplica si ésta no se corrige mediante cirugía y también aumenta si la CIV se asocia a insuficiencia aórtica, sin embargo no tiene relación con el diámetro del defecto (6).

Los mecanismos por los cuales las MCC predisponen a endocarditis bacteriana son la alteración de flujos intracardíacos y producción de turbulencias que ocasionan daño endocárdico y posterior colonización bacteriana. En los pacientes sometidos a cirugía paliativa o correctora el riesgo de endocarditis no desaparece mientras persista algún defecto residual o se introduzca material protésico. Los microorganismos responsables, los criterios diagnósticos y los tratamientos de la endocarditis sobre MCC no difieren de los establecidos para endocarditis que ocurren sobre otras cardiopatías. La esperanza de vida de los pacientes con MCC ha mejorado mucho en los últimos años debido a los progresos en el tratamiento médico y quirúrgico llegando más pacientes a la edad adulta por lo que es de esperar un aumento en la frecuencia de endocarditis sobre esta población al igual que ha ocurrido con la patología valvular degenerativa. Para prevenir la endocarditis en estos pacientes es fundamental la profilaxis antibiótica en todas aquellas situaciones en las que esté indicada. Además, en todos aquellos enfermos con una MCC conocida, corregida o no, que presenten fiebre sin focalidad clínica habrá que considerar el diagnóstico de endocarditis.

A. Perelló Roso, A. Osa Sáez*, M. ${ }^{a}$ P. García Cascó, M. ${ }^{a}$ L. Micó Giner

Servicios de Medicina Interna $y *$ Cardiología. Hospital Univer sitario La Fe. Valencia

1. Saiman I, Prince A, Gersoni WM. Pediatric infective endocarditis in the modern era. J Pediatr 1993;122, 847-53.

2. Martin JM, Neches WH, Wald ER. Infective endocarditis: 35 years of experience at children s hospital. Clin Infect Dis 1997; 24: 669-75.

3. McKinsey DS, Ratts TE, Bisno AL. Underlying cardiac lesions in adults with infective endocarditis. The changing spectrum. Am J Med 1987; 82 681-8.

4. Van der Meer JM, Thompson J, Valkenburg HA, et al. Epidemiology of bacterial endocarditis in the Netherlands. Arch Intern Med 1992; 152: 1863-8.

5. Mansur AJ, Grinberg M, Gallucci SD, et al. Endocardite infecciosa: analise de 300 episodios. RevPortCardiol 1992; 11: 1067-76.

6. Rhodes LA, Keane JF, Keane JP, et al. Long follow-up (to 43 years). of ventricular septal defect with audible aortic regurgitation. Am J Cardiol 1990; 66: 340-5.

7. Freed MD. Infective endocarditis in the adult with congenital heart disease. Cardiol Clin 1993; 11: 589-602.

8. Dodo H, Child JS. Infective endocarditis in congenital heart disease. Cardiol Clin 1996; 14: 383-92.

\section{Pseudotumor orbitario que debuta como edema palpebral bilateral}

\section{Sr. Director:}

Varón de 39 años de edad, con antecedentes de ulcus duodenal, otitis medias supuradas bilaterales con hipoacusia residual, 